\title{
Are women expected to be more generous?
}

\author{
Fernando Aguiar • Pablo Brañas-Garza • \\ Ramón Cobo-Reyes • Natalia Jimenez • \\ Luis M. Miller
}

Received: 18 December 2007 / Revised: 4 January 2008 / Accepted: 4 February 2008 /

Published online: 10 April 2008

(C) Economic Science Association 2008

\begin{abstract}
This paper analyzes if men and women are expected to behave differently regarding altruism. Since the dictator game provides the most suitable design for studying altruism and generosity in the lab setting, we use a modified version to study the beliefs involved in the game. Our results are substantial: men and women are expected to behave differently. Moreover, while women believe that women are more generous, men consider that women are as generous as men.
\end{abstract}

\footnotetext{
We appreciate comments from Josemari Aizpurua, Shoshana Neuman and participants in seminars at Bar-Ilan University, Max Planck Institute of Economics, Univ. Publica Navarra. Tim Cason and one anonymous referee made substantial comments on the previous draft. Financial support from CICYT (SEJ2007-62081/ECON and SEJ2006-00959/SOCI) and FCEA (SOC2.05/43) is gratefully acknowledge. Martha Gaustad revised the English grammar.
}

Electronic supplementary material The online version of this article (http://dx.doi.org/10.1007/s10683-008-9199-z) contains supplementary material, which is available to authorized users.

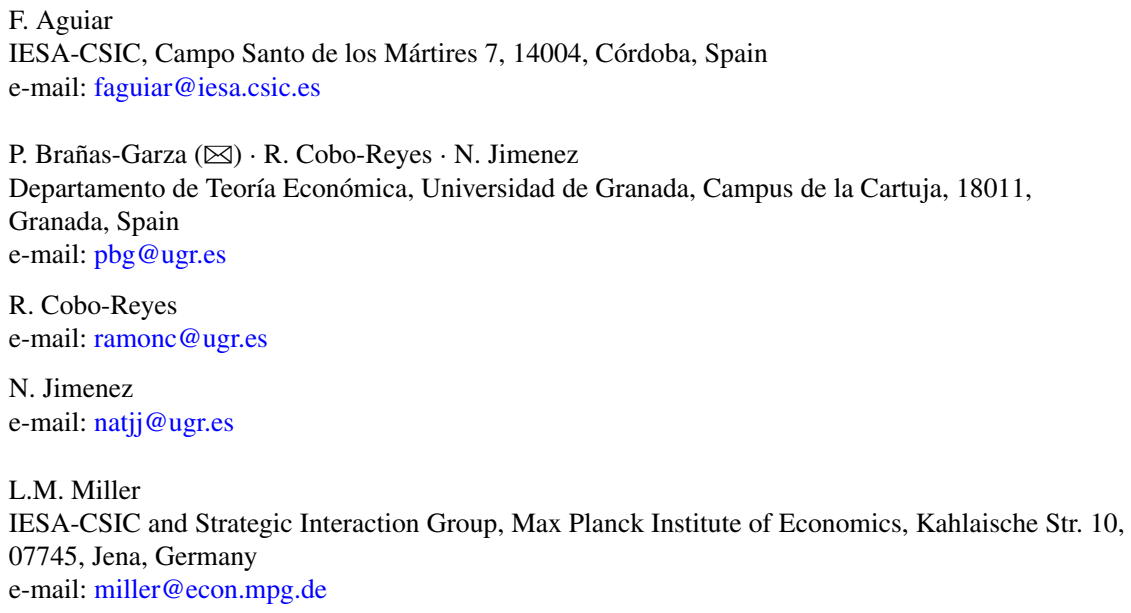


Keywords Dictator game $\cdot$ Beliefs $\cdot$ Expectations $\cdot$ Generosity $\cdot$ Gender

JEL Classification C91 $\cdot$ D64 $\cdot$ J16

\section{Introduction}

A vast amount of literature in the social sciences analyzes differences in behavior between men and women. This includes relevant topics of economic inquiry such as labor segregation, the gender pay gap and patterns of tacit discrimination. In the last two decades, experimentalists have contributed to this research by providing explanations based on the differences in preferences between men and women (see Croson and Gneezy 2006). ${ }^{1}$

Experimental economics have chiefly focused on three different domains in which gender bias is present. First, several experimental and field investigations have shown that women are more risk averse than men (Eckel and Grossman forthcoming). Second, men react very differently than women when facing highly competitive environments (Gneezy et al. 2003; Gneezy and Rustichini 2004; Niederle and Vesterlund 2007). Note that these two findings are also quite consistent with an evolutionary account of sex differences in preferences (Croson and Gneezy 2006).

The third domain where gender differences have been found is that of social preferences. However, as Cox and Deck's (2006) analysis shows, the magnitude and direction of these differences are far from being known and explained. One potential reason for this is the fact that experimental economics research on gender and social preferences have mainly explored behavioral disparities (i.e. differences in revealed preferences). This paper contributes to this debate by exploring differences in beliefs between men and women, that is, not gender differences per se, but how subjects perceive behavioral differences between men and women. ${ }^{2}$

In a first attempt to address perceived gender differences in social preferences, we examine a clear and straightforward question in this paper: Do subjects hold special beliefs for females regarding generosity? This first approximation is related only to individuals' perceived generosity. ${ }^{3}$ To achieve this end, we performed a highly intuitive design. Subjects (recipients) received detailed instructions explaining the dictator game and were then shown two boxes. The box on the left contained 20 dictator allocations made by 20 females, while the box on the right contained another 20 divisions made by 20 males. The experimental subjects were told that they would receive

\footnotetext{
${ }^{1}$ Experimental economists have simply continued a fruitful line of research developed by experimental and social psychologists. For a review of the psychological evidence see Eagly (1995).

${ }^{2}$ Although the question about beliefs of others' generosity has not been adequately addressed by experimental economists, many papers elicit and report the beliefs of participants in situations that trigger social preferences. Specifically, there is some evidence regarding the role played by gender beliefs on social preferences. See, for instance, Eckel and Grossman (2002) on risk-taking and stereotyping or Buchan et al. (2004) on trust.

${ }^{3}$ The Slonim and Gabarino (forthcoming) study shares some similarities with ours, although they analyzed the frequency with which women and men choose a partner for both a Trust and a Dictator Game. Our design mainly differs from that of Slonim and Gabarino in that the subjects in their experiment play the role of both dictator and recipient, while in ours the subjects play only as recipients.
} 
the amount of money written on one, just one, of the slips of paper drawn randomly (with replacement) from one of the two boxes. The subjects' task involved choosing one of the two boxes. ${ }^{4}$ They were also asked to fill out a questionnaire.

The results are substantial: $i$ ) only one-third of the subjects chose the "men" box; ii) almost $80 \%$ of the females chose the "women" box; iii) only $52 \%$ of the males preferred the "men" box.

The rest of the paper is structured as follows: the design is described in Sect. 2, while the results are shown in Sect. 3 followed by a discussion of our main results in Sect. 4.

\section{Experimental design and procedures}

Two different sessions were conducted at the University of Granada (Spain) with 40 and 28 participants, respectively. The subjects were recruited via posters placed throughout the University announcing the experiment. Individuals confirmed their attendance by E-mail. ${ }^{5}$ The two experimental sessions were conducted consecutively. Both experimental sessions were controlled in such a way as to prevent participants from communicating with one another. ${ }^{6}$ On average, each subject earned 8 euros (including a 2.5 euro show-up fee) for a one-hour session.

Subjects were given written instructions ${ }^{7}$ which were also read aloud by the experimenter to ensure that all the participants received the same information. The subjects were not allowed to speak to one another.

The experiment was conducted in two different phases. In the first phase, the subjects were required to make four sequential decisions. ${ }^{8}$ They were then asked to answer a short questionnaire to justify the decisions they had made during the experiment.

In what follows, we focus on the basic task faced by the subjects. Two different boxes labeled "women" and "men" were placed at the front of a room. Each box contained 20 slips of paper. Each slip was printed with the donation made by each of 40 dictators ( 20 women +20 men). The 40 dictators were randomly selected-using a list of random numbers generated by computer-from an entire subject pool that had participated in previous sessions of a standard dictator game. ${ }^{9}$

\footnotetext{
${ }^{4}$ Recall that whereas papers like Eckel and Grossman's (1998) examine if women are more generous than men in DG, we explore if they are expected to be different.

${ }^{5}$ Among the participants, 25 were studying economics, 27 business, 6 engineering and 10 humanities and social sciences. Therefore, we may note that although they are students, they are quite "universal" in origin.

${ }^{6}$ There are no statistical differences between participants' behavior in the sessions regarding the main task of the experiment (Mann-Whitney $Z=-0.149, p=0.881$ ).

${ }^{7}$ Instructions (translation into English) are available on the journal web page as Supplemental Material.

${ }^{8}$ The first part of the experiment involved four steps: choosing a box, drawing a payment card from the box and making two guesses regarding the money they expected to earn. However, only the first step is analyzed in this paper.

${ }^{9}$ This previous dictator game experiment was conducted at the University of Granada in January 2006. In that experiment every participant received ten 50-cent coins and was asked to divide this amount of
} 
Table 1 Subjects' decisions

\begin{tabular}{lllll}
\hline & & Females & Males & Total \\
\hline \multirow{2}{*}{ Gender chosen } & Women & $26(78.7 \%)$ & 17 & $43(63.2 \%)$ \\
& Men & 7 & $18(51.4 \%)$ & 25 \\
& Total & 33 & 35 & 68 \\
\hline
\end{tabular}

The only decision participants had to make was to select the box they preferred (either the "women" or the "men" box). First, they had to write down their decision on a piece of paper (which had a code on the top right corner). After collecting the decision sheets of all the participants, each subject was called to the front of the room with her code to draw one slip of paper from the box she had already chosen. The number printed on the slip of paper corresponded to the amount of money each participant earned. After making note of the corresponding number of coins each participant had earned, the slip of paper was returned to the correct box. Therefore, all the participants had the same number of possible allocations.

The initial intuition underlying this design is based on the assumption that subjects want to maximize their expected payoffs and will therefore tend to choose the box in which they expect to obtain a higher average payoff. Thus, subjects' choices will reveal their beliefs about which sex is more generous in the dictator game.

After completing all the tasks and answering the questionnaire, the payoffs were calculated and the subjects were paid privately in cash.

\section{Results}

We will now explore the participants' decisions. The results are summarized in Table 1 which shows the number of males choosing males and females and the number of females choosing females and males. Table 1 contains the 68 subjects who made the decision.

As reported in Table 1, the "women" box was chosen in $63.2 \%$ of the cases. This effect is even more evident when differentiating by gender (of the subjects choosing the box). We observe that $78.7 \%$ of the females chose the "women" box. In contrast, only $48.6 \%$ of the males chose the "women" box. The $\chi^{2}$-Pearson test supports the hypothesis that the decision-maker's sex does affect the choice of box $\left(\chi^{2}=6.67, p=0.01\right)$.

Result 1 Women consider that they are more generous but males do not reveal any gender bias.

money between herself and another unknown person. The minimum allocation was 0 and the maximum allocation was 5 (only one female allocation was above this range, giving 6 to the recipient). The mean of the 20 randomly selected female allocations was 3.2 and the standard deviation 1.73 , whereas the mean male allocation was 2.45 and the standard deviation 1.96. For more details see Brañas-Garza (2007). 


\section{Conclusion}

This paper addresses the question: which sex is expected to be "more generous"? With this aim we design a very simple mechanism. Subjects have to choose between two different boxes placed in a room labelled "men" and "women". The boxes contain slips of paper printed with the decisions made by players in a previous dictator game. Subjects' payoffs depend on the number printed on the slip of paper. Subjects only have to choose which box (men or women) they want their slip of paper to be randomly drawn from.

Our results show: $i$ ) the majority of the population $(63 \%)$ chose the box of women's donations and ii) this percentage is even stronger for women if we discriminate by gender ( $79 \%$ of women chose the female box). In fact, women were more generous than men in the previous experiment (3.2 vs 2.45 , on average). ${ }^{10}$

The fact that people entertain different beliefs, and thus different expectations, about the actions of men and women could influence labor market behavior in at least two different ways. First, if women are expected to be less competitive, this may result in less job opportunities for women in highly competitive environments (usually the most well-paid). Second, if women are perceived to be more generous, this may lead to labor segregation (with women predominantly being offered caretaker jobs) and a higher number of parental leaves taken by women. As Grimshaw and Rubery (2001) put it:

Moreover, if as a result of accepted patterns of gender behavior and socialization, women are less comfortable in a competitive environment, then this new focus on employability and boundaryless careers may favor men over women.

\section{References}

Brañas-Garza, P. (2007). Promoting helping behavior with framing in dictator games. Journal of Economic Psychology, 28(4), 477-486.

Buchan, N., Croson, R. A., \& Solnick, S. (2004). Trust and gender: an examination of behavior, biases and beliefs in the investment game (Working Paper). University of Wisconsin.

Cooper, D. J., Kagel, J. H., Lo, W., \& Gu, Q. L. (1999). Gaming against managers in incentive systems: experimental results with Chinese students and Chinese managers. American Economic Review, 89, 781-804.

Cox, J., \& Deck, C. (2006). When are women more generous than men? Economic Inquiry, 44(6), 587598.

Croson, R., \& Gneezy, U. (2006). Gender differences in preferences. The Wharton School, Mimeo.

Eagly, A. H. (1995). The science and politics of comparing women and men. American Psychologist, 50, $145-158$.

Eckel, C., \& Grossman, P. J. (1998). Are women less selfish than men?: evidence from dictator experiments. The Economic Journal, 108, 726-735.

Eckel, C., \& Grossman, P. (2002). Sex differences and statistical stereotyping in attitudes toward financial risk. Evolution and Human Behavior, 23(4), 281-295.

\footnotetext{
${ }^{10}$ The reader must keep in mind that our subject pool was composed by university students. The main objection made to this kind of population is the subject pool bias. However, experimental literature has shown that although there are some quantitative subject pool effects, the qualitative patterns of behavior are rather similar across different pools (see Falk and Fehr 2003; Cooper et al. 1999 or Fehr and List 2003), so we could consider obtained results as a first approximation of the populations beliefs.
} 
Eckel, C., \& Grossman, P. J. (forthcoming). Men, women and risk aversion: experimental evidence. In: C. Plott \& V. Smith (Eds.), Handbook of experimental economic results. New York: Elsevier.

Falk, A., \& Fehr, E. (2003). Why labour market experiments? Labour Economics, 10, 399-406.

Fehr, E., \& List, J. (2003). The hidden costs and returns of incentives-trust and trustworthiness among CEOs (WP 134). Institute for Empirical Research in Economics, University of Zurich, Zurich.

Gneezy, U., Niederle, M., \& Rustichini, A. (2003). Performance in competitive environments: gender differences. The Quarterly Journal of Economics, 118(3), 1050-1074.

Gneezy, U., \& Rustichini, A. (2004). Gender and competition at a young age. American Economic Review, 94(2), 377-381.

Grimshaw, D., \& Rubery, J. (2001). The gender pay gap: a research review. Research discussion series. Manchester: Equal Opportunities Commission.

Niederle, M., \& Vesterlund, L. (2007). Do women shy away from competition? Do men compete too much? The Quarterly Journal of Economics, 122(3), 1067-1101.

Slonim, R., \& Garbarino, E. (forthcoming). Increases in trust and altruism from partner selection: experimental evidence. Experimental Economics. 